\title{
Sucrose Permeability: A Simple Non-Invasive Marker of Gastro-Duodenal Damage in Dyspepsia.
}

Tapan Kumar Saha ${ }^{1}$, Arabinda Mohan Bhattarai ${ }^{1}$, Manushree Sharma ${ }^{1}$.

${ }^{1}$ Armed Forces Medical College, Department of Biochemistry, Pune-411040, Maharashtra, India.

\begin{abstract}
Introduction: Diagnosis of gastro-duodenal mucosal damage usually requires endoscopy, an invasive procedure. We made an attemp to assess the clinical validity of sucrose permeability test as a non-invasive marker of gastro-duodenal damage.

Methods: The test was carried out in 65 patients of dyspepsia evaluated by endoscopy and 21 healthy controls. On endoscopy, gastro-duodenal epithelial damage was assessed in all patients of dyspepsia and grouped as: group 1 (normal gastro-duodenal mucosa, $n=18$ ), group 2 (Gastric ulcer, $n=15$ ), group 3 (Duodenal ulcer, $\mathrm{n}=10$ ), group 4 (Gastritis, $\mathrm{n}=12$ ) and group 5 (Duodenitis, $\mathrm{n}=10$ ).

Results: The mean urinary sucrose excretions $(\mathrm{mg})$ in 5 hours after $100 \mathrm{~g}$ oral load was found to be significantly higher in patients of gastric ulcers $(183.6 \pm 169.7$, $p$ value $<0.001)$, duodenal ulcers $(151.7 \pm 79.2$, $p$ value $<0.001)$, gastritis $(115.6 \pm 59.2$, p value $<0.001)$ and duodenitis $(105.2 \pm 122.2$, p value $<0.05)$ as compared to controls (35.2 \pm 17.2$)$. However, the mean sucrose excretion in patients of dyspepsia with normal endoscopic findings $(42.5 \pm 14.8 \mathrm{mg}$ ) was almost similar to the control group ( $\mathrm{p}$ value $>0.05$ ). A ROC curve analysis taking endoscopic findings as gold standard was undertaken to find the optimum cut-off to detect gastro-duodenal epithelial damage.

Conclusions: The cut-off value of $64.5 \mathrm{mg} / 5 \mathrm{~h}$ for urinary sucrose excretion provided the best sensitivity and specificity in the diagnosis of both surgical (gastric and duodenal ulcer) and non-surgical (gastritis and duodenitis) gastro-duodenal mucosal damage. At this cutoff sucrose permeability test provided a sensitivity of $72 \%$ and specificity of $92 \%$. Similarly, a cut-off value of $66.5 \mathrm{mg} / 5 \mathrm{~h}$ of urinary sucrose excretion provided the best sensitivity and specificity in the diagnosis of surgical gastro-duodenal mucosal damage with sensitivity of $72 \%$ and specificity of $97 \%$.
\end{abstract}

Keywords: gastro-duodenal mucosal damage; endoscopy; sucrose excretion test; non-invasive.

\section{INTRODUCTION}

The term dyspepsia is used for a variety of symptoms associated with the upper gastrointestinal tract. The current international definition of dyspepsia is persistent or recurrent pain of discomfort centered in the upper abdomen and excludes those with heartburn alone. Conditions causing dyspepsia include gastroesophageal reflux disease, peptic ulcer disease, gastric cancer and gall bladder disease. Other less common causes include pancreatic and liver diseases ${ }^{1,2}$.

Globally, the prevalence of uninvestigated dyspepsia (UD) varies between $7 \%$ - 45\%, depending on definition used and geographical location, whilst the prevalence of functional dyspepsia (FD) has been noted to vary between $11 \%-29.2 \%$. Risk factors for FD have been shown to include females and underlying psychological

Correspondence:

Dr. Arabinda Mohan Bhattarai,

Department of Biochemistry, Armed Forces Medical College, Pune-40

Email: arabinda.bhattarai@gmail.com 
disturbances, while environmental lifestyle habits such as poor socio-economic status, smoking, increased caffeine intake and ingestion of non-steroidal antiinflammatory drugs appear to be more relevant to $\mathrm{UD}^{3}$.

Endoscopy is an accurate but impractical tool for routine screening for gastrointestinal damage in patients of dyspepsia. A non-invasive procedure, sucrose permeability test for ulcer detection has been described in population having high per capita consumption of non-steroidal anti-inflammatory drugs (NSAIDS) ${ }^{4}$. The test is based on the fact that the healthy gastrointestinal mucosa is relatively impermeable to disaccharides such as sucrose. Any breach in the mucosa would allow sucrose to get into the circulation. Sucrose is not metabolized in the body and is readily filtered by the kidneys to appear in the urine. As sucrose is rapidly hydrolyzed in the jejunum to glucose and fructose, the increased amounts of sucrose in urine after an oral load would suggest gastrointestinal epithelial damage proximal to jejunum. The test being simple, cheap and readily acceptable to patients, a study was undertaken to assess applicability of this test in population where per capita consumption of NSAIDS is not so high ${ }^{5}$.

\section{METHODS}

We recruited 21 healthy controls and 65 patients with present or past history of pain epigastrium, melena or hematemesis or dyspepsia who underwent endoscopy at gastroenterology clinic of a tertiary care center. The individuals included in the control group had not used any NSAIDS in past three months. Patients with previous gastric surgery or patients having intestinal malabsorption syndrome like celiac disease were excluded from the study.

Gastrointestinal epithelial damage of dyspepsia patients was assessed endoscopically as follows:

Group 1: Normal appearance of gastro-duodenal mucosa on endoscopy

Group 2: Gastric ulceration (a lesion of over $5 \mathrm{~mm}$ and/or causing a depression in the gastric mucosal surface).

Group 3: Duodenal ulcer (a lesion of over $5 \mathrm{~mm}$ and/ or causing a depression in the duodenal mucosal surface).

Group 4: Gastritis (scattered erosions of hemorrhages in gastric mucosa).
Group 5: Duodenitis (scattered erosions in the duodenal cap).

For collection of samples, patients were advised to come at 8 a.m. after an overnight fast. Individuals were asked to void the bladder and were given $100 \mathrm{~g}$ sucrose powder dissolved in $500 \mathrm{~mL}$ of water to drink in 10 minutes. The urine passed during next 5 hours period was collected and volume measured. The samples were stored at $4 \mathrm{OC}$ pending analysis.

Estimation of sucrose in urine was carried out, indirectly by hydrolyzing sucrose with enzyme invertase form one molecule each of glucose and fructose [6]. Glucose so produced (X1) was measured by glucose oxidase-peroxidase method using reagent kit (Erba) and absorbance was noted at $505 \mathrm{~nm}$ by ErbaTransasiaAutoanalyser (EM-360). The internal QC of glucose for level 1 Biorad is $80 \pm 5$, and level 2 Biorad is $290 \pm 10$. Glucose present in urine prior to hydrolysis was also determined (X2) to calculate sucrose excretion using the following formula:

Sucrose excretion $(\mathbf{m g} / \mathbf{5 h})=(\mathrm{X} 1-\mathrm{X} 2) \times 1.9 \times$ Vol of urine ( $\mathrm{mL}$ in $5 \mathrm{hrs}$.)

Where $\mathrm{X} 1=$ Urinary glucose $(\mathrm{mg} / \mathrm{mL})$ after hydrolysis

$\mathrm{X} 2=$ Urinary glucose $(\mathrm{mg} / \mathrm{mL})$ before hydrolysis

\section{RESULTS}

All patients of gastric ulcer, duodenal ulcer, gastritis and duodenitis had significantly higher average 5 hours urinary sucrose excretion than the healthy controls. However, the mean sucrose excretion in patients of dyspepsia with normal endoscopic, findings was almost similar to control group and the difference was statistically not significant $(\mathrm{p}>0.05)$. The sucrose excretion (mean $\pm \mathrm{SD}$ ) for different patient groups and controls is depicted in the Table 1.

A ROC curve analysis, taking endoscopic findings for gastro-duodenal epithelial damage as gold standard was done. Group 2 and 3 were considered surgical mucosal damage (SMD) and group 4 and 5 as nonsurgical mucosal damage (NSMD). The ROC curve revealed that the cut-off point of $64.5 \mathrm{mg}$ provided the best sensitivity $(72 \%)$ and specificity (92\%) for the diagnosis of both surgical and non-surgical gastro-duodenal mucosal damage (group 2, 3, 4 and 5 combined). A cut-off value of $66.5 \mathrm{mg}$ provided the 
best sensitivity ( $72 \%$ ) and specificity (97\%) for surgical mucosal damage (group 2 and 3 combined) (Table 2).

Table 1. Mean sucrose excretion in 5 hours in different groups of patients of dyspepsia and controls.

\begin{tabular}{|l|l|l|l|}
\hline Group & $\begin{array}{l}\text { No of } \\
\text { individuals }\end{array}$ & $\begin{array}{l}\text { Sucrose } \\
\text { excretion }(\mathrm{mg} / 5 \\
\text { hrs) } \\
\text { Mean } \pm \text { SD } \\
\text { (range) }\end{array}$ & P value \\
\hline Control (Gr.0) & 21 & $\begin{array}{l}35.2 \pm 17.2(12.8- \\
66.1)\end{array}$ & - \\
\hline $\begin{array}{l}\text { Dyspepsia } \\
\text { Endoscopically } \\
\text { normal mucosa } \\
\text { (Gr. } 1)\end{array}$ & 18 & $\begin{array}{l}42.5 \pm 14.8(24.0- \\
68.6)\end{array}$ & $\begin{array}{l}\text { Not } \\
\text { significant } \\
\end{array}$ \\
\hline $\begin{array}{l}\text { Gastric ulcer } \\
\text { (Gr.2) }\end{array}$ & 15 & $\begin{array}{l}183.6 \pm 169.7 \\
(46.2-590.0)\end{array}$ & $<0.001$ \\
\hline $\begin{array}{l}\text { Duodenal ulcer } \\
\text { (Gr.3) }\end{array}$ & 10 & $\begin{array}{l}151.7 \pm 79.2 \\
(23.7-285.1)\end{array}$ & $<0.001$ \\
\hline Gastritis (Gr.4) & 12 & $\begin{array}{l}115.6 \pm 59.2 \\
(46.0-228.0)\end{array}$ & $<0.001$ \\
\hline Duodenitis (Gr.5) & 10 & $\begin{array}{l}105.2 \pm 122.2 \\
(16.4-426.0)\end{array}$ & $<0.05$ \\
\hline
\end{tabular}

Figure 1.Sucrose excretion in healthy controls and dyspepsia patients with gastro-duodenal mucosal damage.

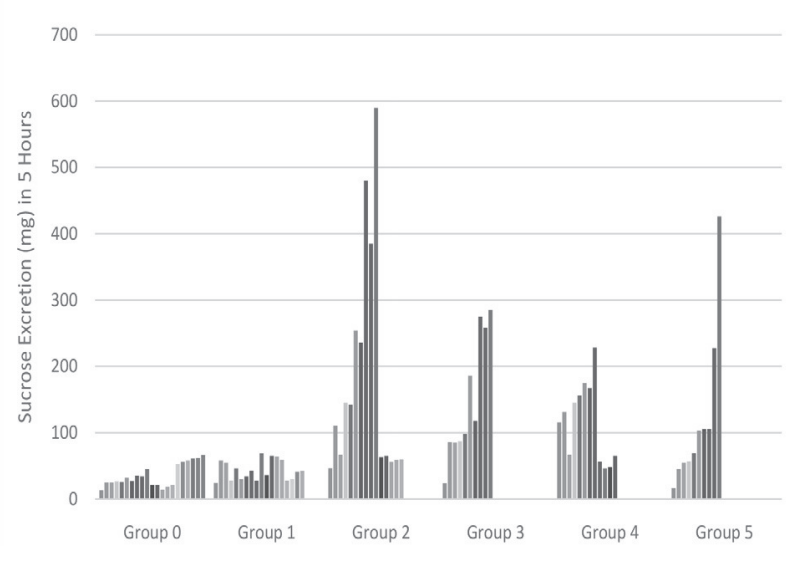

Table 2.The sensitivity and specificity at different cut-off values of sucrose excretion for surgical mucosal damage and all cases mucosal damage (surgical and non-surgical).

\begin{tabular}{|l|l|l|l|l|}
\hline \multirow{2}{*}{$\begin{array}{l}\text { C u t- } \\
\text { off }\end{array}$} & \multicolumn{2}{|l|}{$\begin{array}{l}\text { Only surgical mucosal } \\
\text { damage }\end{array}$} & $\begin{array}{l}\text { All cases of mucosal } \\
\text { damage (surgical and } \\
\text { non-surgical }\end{array}$ \\
\cline { 2 - 5 } & Sensitivity (\%) & $\begin{array}{l}\text { Specificity } \\
(\%)\end{array}$ & $\begin{array}{l}\text { Sensitivity } \\
(\%)\end{array}$ & $\begin{array}{l}\text { Specificity } \\
(\%)\end{array}$ \\
\hline 46.1 & 96 & 69 & 91.5 & 69 \\
\hline 55.5 & 92 & 74 & 85 & 74 \\
\hline 62.5 & 80 & 80 & 74 & 90 \\
\hline 64.5 & 76 & 92 & 72 & 92 \\
\hline 66.5 & 72 & 97 & 68 & 97 \\
\hline 76.8 & 68 & 100 & 61 & 100 \\
\hline
\end{tabular}

\section{DISCUSSION}

Many authors have noted that abnormal endoscopic findings of upper gastrointestinal mucosa are associated with increased sucrose excretion. They reported that urinary sucrose excretion is a good marker of gastrointestinal mucosal damage and may be used as a screening test in large groups of population ${ }^{7,8}$.

Molecules such as disaccharides cross the healthy gastrointestinal mucosa poorly. However, with epithelial damage, there is an increased permeation of these molecules. This observation has been found to be clinically useful and now several intestinal diseases can be detected using a variety of permeability markers? Sucrose permeability in the gut is increased in gastroduodenal mucosal damage resulting in its increased excretion in urine after an oral load. After crossing the duodenum, sucrose is completely hydrolyzed into glucose and fructose in proximal jejunum. Any mucosal injury proximal to jejunum will allow absorption of unhydrolysed sucrose which is not metabolized, readily filtered by the kidneys and appears in the urine. Therefore, the urinary sucrose can be used as an indirect measure of gastro-duodenal muosal damage ${ }^{10}$.

In the present study, we found that mean sucrose excretion was significantly increased in presence of gastro-duodenal epithelial damage. Sucrose excretion was found to be highest in gastric ulcer patients. However in patients of duodenitis, the mean sucrose excretion was relatively lower (105.2 $\mathrm{mg}$ in 5 hours) than in other groups of mucosal damage. These patients also had a significant overlap of sucrose excretion with normal healthy individuals. This could probably be due to a short contact period of the sucrose solution with the damaged duodenal mucosa because of relatively rapid passage of food through duodenum. However, in patients of duodenal ulcers the mean sucrose excretion in 5 hours was relatively higher $(151.7 \mathrm{mg})$ than duodenitis. This could either be due to the larger gap in the mucosa allowing faster diffusion or due to structural deformity resulting in longer contact time between the sucrose solution and damaged duodenal mucosa. 
Fig. 2 ROC Curve for the diagnosis of surgical mucosal damage by sucrose excretion test.

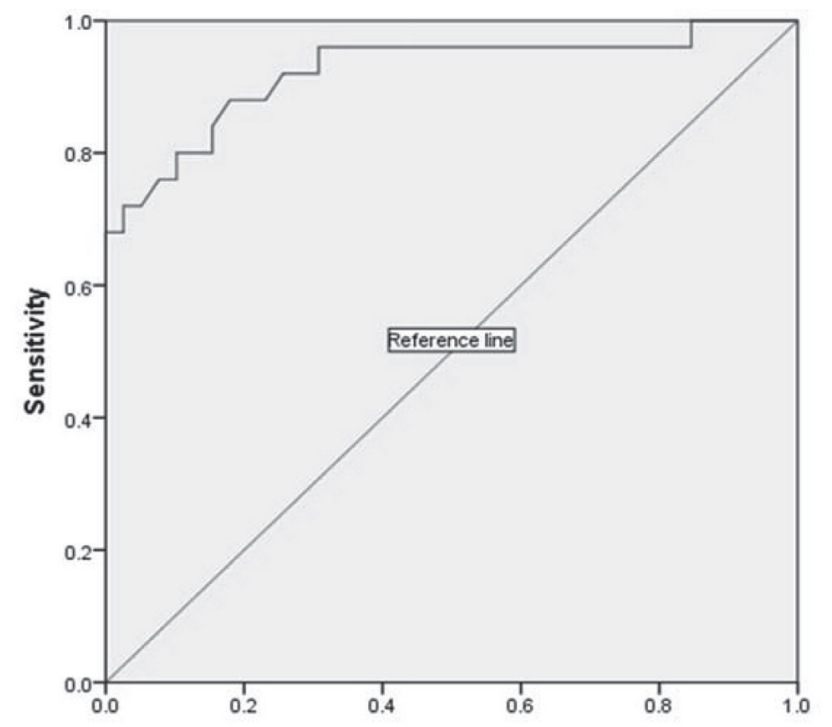

Fig. 3 ROC Curve for the diagnosis of all cases of mucosal damage (surgical and non-surgical) by sucrose excretion test.

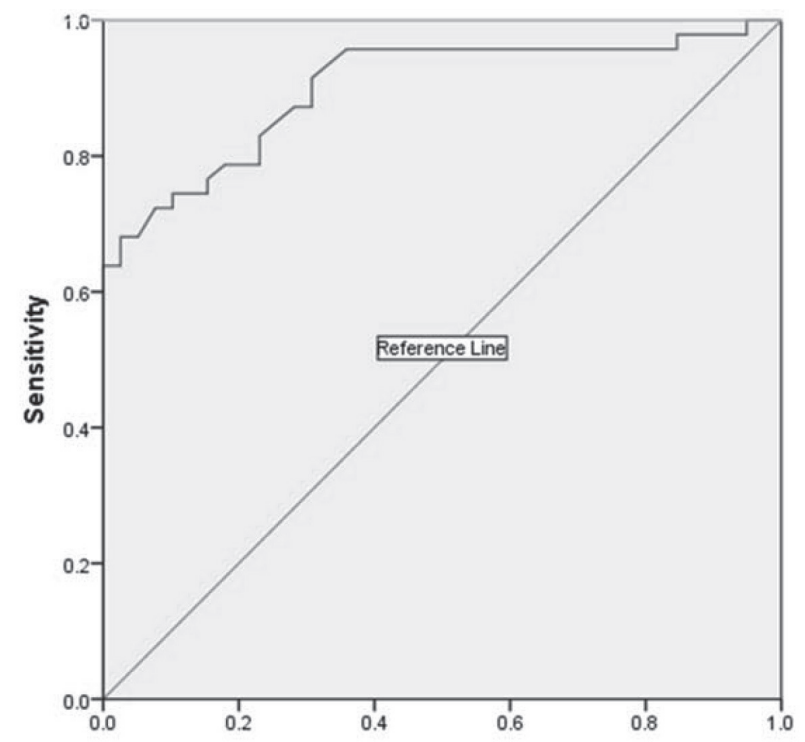

The area under the ROC curve is higher for surgical mucosal damage (0.924) as compared to all cases of mucosal damage (0.901). Therefore, the test has good diagnostic value in patients of surgical mucosal damage.

The cut-off value can be set depending upon the objective of the test viz. screening or diagnostic purpose. For example, at a cut-off value of $62.5 \mathrm{mg}$, sucrose excretion test has a sensitivity of $80 \%$ for SMD and $74 \%$ for all cases of mucosal damage, and a specificity of $80 \%$ for SMD and $90 \%$ for all types of mucosal damage. At this cut-off value the test has good screening significance for surgical mucosal damage but good diagnostic value for all types of mucosal damages. Patients having excretion more than this cut-off may undergo endoscopy for confirmatory diagnosis.

\section{CONCLUSIONS}

Sucrose permeability test is a simple, cheap and readily acceptable by patients as compared to endoscopy. It could be used to sequentially follow patients at risk of upper GI disease, such as chronic NSAIDS users. By noting a change in the permeability of gastroduodenal mucosa for sucrose in dyspepsia patients, it is possible to intervene therapeutically before the disease becomes clinically detectable. Although its diagnostic sensitivity is poor in patients of duodenitis, by selecting an appropriate cut-off value it can be used to diagnose other upper GI mucosal damage. Though it cannot replace endoscopy, it can limit the number of cases who would require endoscopy. This test would also be useful to assess any improvement or progress in patients on treatment for gastro-duodenal damage other than duodenitis.

\section{REFERENCES}

1. Tack J, Talley NJ, Camilleri M, Holtmann G, Hu P, Malagelada J-R, et al. Functional gastroduodenal disorders. Gastroenterology. 2006;130(5):1466-79.http://dx.doi. org/10.1053/j.gastro.2005.11.059

2. Tytgat G. Role of endoscopy and biopsy in the work up of dyspepsia. Gut. 2002;50(suppl IV):iv13-iv6.http://dx.doi. org/10.1136/gut.50.suppl 4.iv13

3. Mahadeva S, Goh K-L. Epidemiology of functional dyspepsia: a global perspective. World Journal of Gastroenterology. 2006;12(17):2661.

4. Maino M, Mantovani N, Merli R, Cavestro GM, Leandro G, Cavallaro LG. Effects of chronic therapy with nonsteroidealantinflammatory drugs on gastric permeability of sucrose: A study on 71 patients with rheumatoid arthritis. World J Gastroenterol 2006 August 21; 12(31): 5017-20.

5. Shishido T, Yamaguchi T, Odaka T, Seimiya M, Saisho H, Nomura F. Significance of a novel sucrose permeability test using serum in the diagnosis of early gastric cancer. World Journal of Gastroenterology. 2005;11(44):6905.

6. Hessels J, Snoeyink EJ, Platenkamp AJ, Voortman G, Steggink J, Eidhof HH. Assessment of intestinal permeability: enzymatic determination of urinary mannitol, 
MJSBH July-December 2014|Vol 13| Issue 2

raffinose, sucrose and lactose on Hitachi analyzer. Clinical chemistry and laboratory medicine. 2003;41(1):33-8.http:// dx.doi.org/10.1515/CCLM.2003.007

7. Smecuol E, Bai JC, Sugai E, Vazquez H, Niveloni S, Pedreira S. Acute gastrointestinal permeability responses to different non-steroidal anti-inflammatory drugs. Gut 2001;49:650-5.http://dx.doi.org/10.1136/gut.49.5.650

8. Butler RN. Measuring tools for gastrointestinal toxicity. Current Opinion in Supportive and Palliative
Care 2008;2:35-9. $\quad$ http://dx.doi.org/10.1097/

SPC.0b013e 3282f41b71

9. SalimSaY, So"derholm JD. Importance of Disrupted Intestinal Barrier in Inflammatory Bowel Diseases.Inflamm Bowel Dis 2011;17:362-81. http://dx.doi.org/10.1002/ ibd. 21403

10. Teshima CW, Dieleman LA, Meddings JB. Abnormal intestinal permeability in Crohn's disease pathogenesis. Ann NY Acad Sci2012;159-165.http://dx.doi.org/10.1111/ j.1749-6632.2012.06612.x 